Mário César Ferreira ${ }^{1}$

${ }^{1}$ Universidade de Brasília, Instituto de Psicologia. Brasília, DF, Brasil.

Contato:

Mário César Ferreira

E-mail:

mcesar@unb.br

O trabalho foi subvencionado por meio do pagamento de bolsa de produtividade em pesquisa pelo CNPq e de pós-doutoramento pela Capes. Os diferentes tipos de aporte cobrem o período de 2000-2013. Os números dos processos são: Conselho Nacional de Desenvolvimento Científico e Tecnológico (CNPq) processos n. 465491/2000-6 (edital universal); Conselho Nacional de Desenvolvimento Científico e Tecnológico (CNPq) processo n. 551376/2002-3 (projeto integrado de pesquisa); Conselho Nacional de Desenvolvimento Científico e Tecnológico (CNPq) processo n. 305081/2004-7 (bolsa de produtividade em pesquisa); Conselho Nacional de Desenvolvimento Científico e Tecnológico (CNPq) processo n. 300319/2007-0 (bolsa de produtividade em pesquisa); Coordenação de Aperfeiçoamento de Pessoal de Nível Superior (Capes) processo n. 4627/06-7 (bolsa de pós-doutorado, período 29/03/2007 a 13/02/2008);

Conselho Nacional de Desenvolvimento Científico e Tecnológico (CNPq) processo n. 309174/2010-4 (bolsa de produtividade em pesquisa).

O autor declara não haver conflitos de interesses.

Recebido: 13/02/2013

Revisado: 29/07/2014

Aprovado: 01/08/2014

\section{Ergonomia da Atividade aplicada à Qualidade de Vida no Trabalho: lugar, importância e contribuição da Análise Ergonômica do Trabalho (AET)}

\author{
Activity-Centered Ergonomics applied to Quality of Life at Work: \\ role, importance, and contribution of the Ergonomic Work \\ Analysis (EWA)
}

\section{Resumo}

Introdução: o método clássico da Ergonomia da Atividade, a Análise Ergonômica do Trabalho (AET), consolidou-se no campo das ciências do trabalho como um instrumento eficaz para operacionalizar a perspectiva de compreender o trabalho para transformá-lo. Objetivo: o artigo relata uma experiência de uso heterodoxo da AET situando seu papel instrumental no nível analítico microergonômico da abordagem intitulada "Ergonomia da Atividade Aplicada à Qualidade de Vida no Trabalho (EAA_QVT)”. Método: a análise de demanda específica - ponto de partida da AET -, proveniente de dirigentes, gestores e técnicos no contexto do serviço público brasileiro, está na gênese da construção dessa abordagem que articula a Ergonomia da Atividade e a Qualidade de Vida no Trabalho (QVT). Resultados: com base na apresentação panorâmica dos fundamentos teóricos e metodológicos da EAA_QVT, busca-se ilustrar a aplicação singular da AET, situando o seu lugar, a sua importância e sua contribuição como recurso instrumental imprescindível para uma avaliação mais profunda dos fatores que impactam na QVT nas organizações. Conclusão: os resultados produzidos pela aplicação da EAA_QVT possibilitam gerar recomendações para as atividades de vigilância, assistência e promoção da saúde e segurança no trabalho.

Palavras-chave: ergonomia da atividade; análise ergonômica do trabalho; qualidade de vida no trabalho.

\begin{abstract}
Background: the classical method of activity-centered ergonomics, the Ergonomic Work Analysis (EWA), is now consolidated in the labor sciences field as an effective tool to operationalize the perspective of understanding labor in order to transform it. Objective: this study reports the heterodox use of EWA, specifying its instrumental role at the micro-ergonomic analytical level of the following approach: "Activity-Centered Ergonomics Applied to Quality of Life at Work (AEA QLW)". Methods: the specific demand analysis, the starting point of EWA, originated from managers, directors and technicians in the Brazilian public service, is the origin of this approach, which articulates Activity-Centered Ergonomics and Quality of Life at Work. Results: based on the overall view of the theoretical and methodological principles of AEA_QLW, this study illustrates the unique application of EWA, specifying its role, the importance, and the contribution as essential instrumental resource for a deeper assessment of the factors that impact QLW in organizations. Conclusion: the results produced by the application of AEA_QLW have generated recommendations for the surveillance, care and promotion of occupational health and safety activities inside organizations.
\end{abstract}

Keywords: activity-centered ergonomics; Ergonomic Work Analysis; quality of life at work. 


\section{Introdução}

O objetivo deste relato é mostrar o lugar, a importância e a contribuição da Análise Ergonômica do Trabalho (AET) com base em uma visão panorâmica da abordagem intitulada "Ergonomia da Atividade Aplicada à Qualidade de Vida no Trabalho (EAA_QVT)” (FERREIRA, 2012a). Trata-se, portanto, de relato sucinto de uma experiência em construção dessa abordagem no contexto contemporâneo das organizações, especialmente ancorada em aplicações no setor público federal brasileiro. Tendo em vista essa perspectiva analítica, uma questão inicial se impõe: Qual é a relevância deste relato no escopo deste dossiê temático da Revista Brasileira de Saúde Ocupacional (RBSO)?

A relevância do presente relato se inscreve em um cenário mais global e contempla três dimensões principais e interdependentes, a saber:

- Do ponto de vista contemporâneo, o mundo do trabalho passa por aceleradas transformações com base em um processo de reestruturação produtiva (LEITE, 2003; ANTUNES; ALVES, 2004) que tem produzido indicadores negativos para a saúde e para a segurança dos trabalhadores (p. ex.: epidemia de DORT, crescimento dos casos de síndrome de Burnout, aumento de acidentes de trabalho). O sentimento de intensificação do trabalho e de trabalhar no limite das capacidades se faz cada vez mais presente nos relatos dos trabalhadores. É nesse contexto característico do limiar do século XXI que as ciências do trabalho e da saúde estão sendo convocadas para a produção de quadros explicativos sobre o nexo trabalho-saúde-segurança e, em consequência, para a proposição de recomendações de mudanças que, a um só tempo, combinem bem-estar dos trabalhadores, satisfação de clientes e usuários, eficiência e eficácia dos processos produtivos. Nessa perspectiva, o background instrumental da Ergonomia da Atividade (MONTMOLLIN, 1990; LAVILLE, 1993; WISNER, 1994), a AET, constitui-se e tem se constituído em imprescindível "ferramenta" para compreender o trabalho e transformá-lo;

- Do ponto de vista das organizações públicas, privadas e não governamentais, o uso da Ergonomia da Atividade e da aplicação do seu método, a AET, tem se revelado promissor nos contextos corporativos e normativos. A vasta produção bibliográfica (GUÉRIN et al., 1997; GROSJEAN; WEERDT, 2005) no campo da Ergonomia da
Atividade mostra que a AET vem contribuindo decisivamente na produção de melhorias que aprimoram os contextos de trabalho, agregando mais segurança, eficiência e eficácia dos processos de trabalho e impactando também no bem-estar dos trabalhadores e na satisfação de usuários e clientes. Transformar a própria AET em objeto de reflexão mais aprofundada certamente contribui para aprimorar a sua aplicação nos contextos corporativos. Uma aplicação que efetivamente ajude dirigentes, gestores, técnicos e trabalhadores a construir e a implantar soluções que eliminem ou minimizem os problemas humanos, organizacionais e sociais que habitam o mundo do trabalho atual;

- Do ponto de vista acadêmico, o debate, de natureza epistemológica, sobre o uso diverso e singular da AET como instrumento metodológico (DANIELLOU, 1996) e sobre suas contribuições no caso brasileiro dá visibilidade para o estado da arte. Não só isso. Permite identificar divergências, convergências, limites, aportes e potencialidades que nascem da aplicação da AET, a qual, por sua vez, contribui na produção de conhecimento sobre os problemas e sobre os desafios que marcam a inter-relação indivíduo-trabalho-organização. Um confronto de perspectivas, de caráter salutar, que pode impulsionar o próprio desenvolvimento da AET como "ferramenta" de investigação apropriada para se conhecer o mundo do trabalho para além de sua aparência.

As reflexões sobre o uso da AET no contexto de trabalho brasileiro são, portanto, oportunas e alinhadas com os grandes desafios que estão postos às ciências do trabalho e da saúde no país. É com base nos ingredientes que compõem esse cenário mais global que se inscreve a temática deste artigo, cuja perspectiva é mostrar o lugar e a importância da AET na abordagem EAA_QVT, nascida das especificidades da análise de demandas na região Centro-Oeste brasileira.

\section{Gênese da Ergonomia da Atividade Aplicada à Qualidade de Vida no Trabalho}

O ponto de partida de construção da abordagem EAA_QVT se situa nas especificidades assumidas em uma etapa estratégica da AET - a análise da demanda (GUÉRIN et al., 1997) - em um determinado contexto de aplicação da Ergonomia da Atividade. A análise das demandas ${ }^{2}$ para intervenção ergonômica que

\footnotetext{
2 Demandas diversas, oriundas do setor terciário da economia, como: impactos da diferença entre trabalho prescrito e real; precária usabilidade de interfaces informatizadas; sobrecarga no trabalho do caixa de supermercado (FERREIRA; ARAÚJO; ARAÚJO, 1998; GONÇALVES; FERREIRA, 1999; FREIRE; FERREIRA, 2000).
} 
chegavam aos docentes-pesquisadores impôs repensar a pertinência da AET como instrumento de diagnóstico. Um repensar que, paulatinamente, fez nascer a EAA_QVT. Mas que especificidades foram essas?

Tais especificidades foram, fundamentalmente, as seguintes: (a) o contexto de intervenção ergonômica se situa no Centro-Oeste brasileiro distante dos núcleos industriais da região Sudeste do país; (b) a região onde se estruturou a EAA_QVT, especialmente a cidade, tem uma economia ancorada no setor de serviços e comércio, cujo tecido industrial é incipiente, residual; (c) a cidade, por ser a sede administrativa do poder executivo federal brasileiro, tem milhares de servidores trabalhando na rede de órgãos públicos que a compõe; (d) os serviços públicos prestados se estendem para todo o Brasil, transformando os órgãos públicos em esferas administrativas estratégicas dos poderes da República. É nesse cenário singular que as demandas mais recorrentes - que chegavam ao nosso "Grupo de Estudos e Pesquisas Aplicadas ao Setor Público (ErgoPublic)” - trazidas, principalmente, por dirigentes, gestores e técnicos do serviço público federal diziam respeito a problemas predominantemente macro-organizacionais, ou seja, que abrangiam a organização como um todo, e não apenas unidades específicas.

Tais demandas focavam diferentes aspectos, de natureza mais global que específicas, como: (a) houve uma reconversão tecnológica no órgão como um todo e, desde então, aumentaram-se os casos de afastamentos do trabalho; (b) o que fazer em face das licenças-saúde que vêm crescendo assustadoramente na instituição; (c) o absenteísmo, a falta de comprometimento e de engajamento com as tarefas impactam negativamente na produtividade e na qualidade dos serviços prestados; (d) o que fazer para alavancar os índices de satisfação com o trabalho Além dessas questões, a mais recorrente foi: Como promover a Qualidade de Vida no Trabalho (QVT) para todos os servidores de um dado órgão público? Eis alguns exemplos de demandas que chegavam, invariavelmente, acompanhadas de duas perguntas: O que a ergonomia pode fazer para mudar essa situação global preocupante? De que forma a abordagem da ergonomia pode auxiliar os gestores e os técnicos de equipes multiprofissionais no enfrentamento desses grandes desafios?
As demandas chegavam sempre com um viés peculiar: dirigentes, gestores e técnicos do setor público federal buscando resolver macroproblemas organizacionais com base em indicadores críticos e em queixas globais presentes nas organizações. Até então, a experiência do ErgoPublic tinha se concentrado em atender a demandas pontuais, principalmente, relacionadas à "usabilidade de artefatos informatizados" e aos "serviços de atendimento ao público". Os estudos pontuais em pequenos grupos e em poucas unidades de uma organização estavam, portanto, na berlinda. Ela revelava limites na sua aplicação.

Tal conjuntura impeliu um repensar sobre a necessidade de uma nova estratégia de intervenção da Ergonomia da Atividade que atendesse às especificidades das demandas e, consequentemente, reposicionasse o lugar e a importância da AET no desenho de uma nova abordagem, mais ampla. A construção dessa nova estratégia e as reflexões inerentes produzidas fizeram nascer, portanto, a EAA_QVT, cujas principais características e fundamentos são apresentados a seguir.

\section{Ergonomia da Atividade aplicada à Qualidade de Vida no Trabalho: fundamentos teóricos e metodológicos}

Os programas de QVT que operacionalizam práticas assistencialistas ${ }^{3}$ buscam compensar os desgastes vivenciados pelos trabalhadores nos ambientes corporativos por meio do oferecimento de um "cardápio de atividades" do tipo antiestresse (p. ex.: ioga laboral). Contrariamente ao que preconiza a ergonomia (adaptar o trabalho ao ser humano), a abordagem assistencialista de QVT revela importantes limites: é de natureza paliativa (as causas mais profundas do mal-estar no trabalho permanecem intocáveis); é de caráter compensatório (as atividades visam minimizar os efeitos dos desgastes); apoia-se no paradigma do trabalhador como a variável de ajuste. A EAA_QVT visa operacionalizar outra concepção de QVT. O fator “organização do trabalho" (LACAZ, 2000), por exemplo, encontra-se fortemente ausente no enfoque assistencialista.

O conceito que orienta o enfoque de QVT de viés contra-hegemônico se apoia em duas dimensões interdependentes:

\footnotetext{
3 A visão da EAA_QVT apresentada neste relato é, como já salientado, bastante panorâmica. A obra que aborda de forma mais completa essa abordagem - "Ergonomia da Atividade. Uma abordagem centrada no olhar dos trabalhadores" - foi publicada, inicialmente, em 2011 e revisada e ampliada em Ferreira (2012a). Essa obra de referência é o resultado de diversas pesquisas realizadas pelo ErgoPublic, da participação em inúmeros eventos científicos e da produção bibliográfica. Neste último caso, a EAA QVT nasce de reflexões em dois artigos seminais (FERREIRA, 2008, 2011) e em um verbete publicado no Dicionário de Trabalho e Tecnologia por três edições, sendo a mais recente no formato de e-book (FERREIRA, 2012b). Nessa produção bibliográfica, busca-se, teórica e metodologicamente, guardar distância e demarcar diferenças fundamentais com a abordagem hegemônica que, atualmente, orienta as práticas de QVT nas organizações públicas e privadas. Tais práticas, metaforicamente, assemelham-se ao "ofurô corporativo" (FERREIRA, 2006).
} 
- Sob a ótica das organizações, a QVT é um preceito de gestão organizacional que se expressa por um conjunto de normas, diretrizes e práticas no âmbito das condições, da organização e das relações socioprofissionais de trabalho que visa à promoção do bem-estar individual e coletivo, o desenvolvimento pessoal dos trabalhadores e o exercício da cidadania organizacional nos ambientes de trabalho;

- Sob a ótica dos trabalhadores, ela se expressa por meio das representações globais (contexto organizacional) e específicas (situações de trabalho) que estes constroem, indicando o predomínio de experiências de bem-estar no trabalho, de reconhecimento institucional e coletivo, de possibilidade de crescimento profissional e de respeito às características individuais (FERREIRA, 2012a, p. 172).

É nesta segunda dimensão - representações dos trabalhadores (WEILL-FASSINA; RABARDEL; DUBOIS, 1993) - que o modelo teórico da EAA_QVT se apoia e estrutura o seu delineamento investigativo. A primeira dimensão conceitual de viés organizacional, por sua vez, pode ser operacionalizada por meio dos produtos (política e programa de QVT) gerados pela aplicação da abordagem.

O modelo teórico da EAA_QVT, de natureza descritiva, contempla níveis analíticos, fatores estruturadores e métodos voltados para a avaliação da QVT sob a ótica da Ergonomia da Atividade (FERREIRA, 2012a). O recurso da modelização, nesse caso, filia-se à perspectiva proposta por Amalberti, Montmollin e Theureau (1991). Os modelos em ergonomia, segundo os autores, caracterizam-se por um corpo de conhecimentos datados, logo provisórios, que servem de instrumento de inferência para a validação de dados empíricos coletados e que têm uma finalidade heurística para explicar o mecanismo e os fatores que influenciam as condutas dos indivíduos em situação de trabalho. O modelo teórico em EAA_QVT não tem, portanto, a pretensão de substituir o real do trabalho, mas contribuir para descrever os elementos constituintes-chave para uma avaliação da QVT. Ele é de natureza mais descritiva que explicativa. A Figura 1 apresenta globalmente o modelo teórico utilizado na EAA_QVT.

Para manter alinhamento com o objetivo geral deste relato de experiência, apresentar-se-á, inicialmente, uma descrição do modelo e de seus atributos - situando o lugar e a importância da AET - e, em seguida, buscar-se-á apresentar um exemplo prático de aplicação, utilizando esse modelo.

O objeto QVT nessa abordagem é avaliado com base em dois níveis analíticos interdependentes: macroergonômico e microergonômico

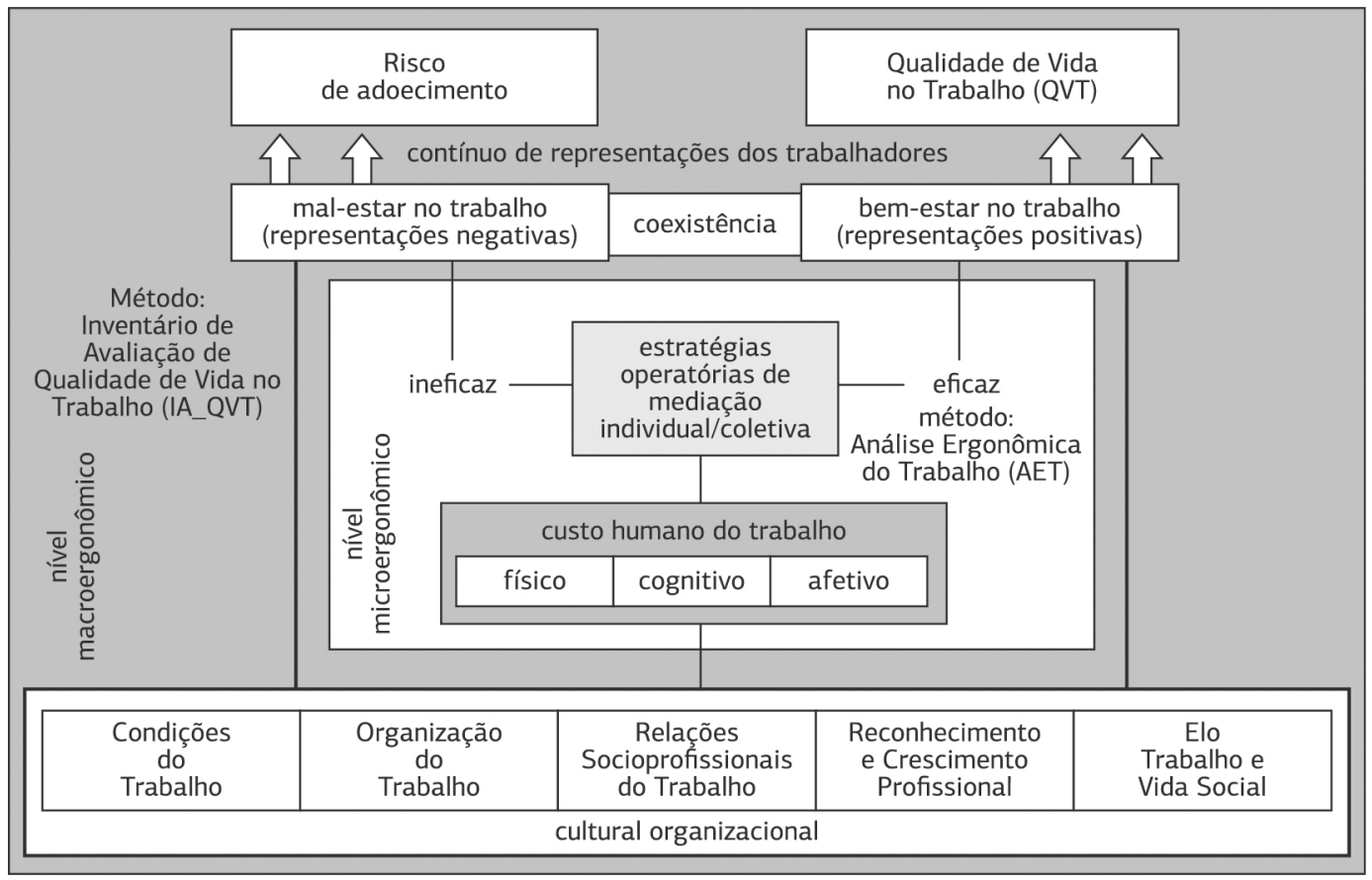

Figura 1 Modelo descritivo teórico-metodológico da EAA_QVT: níveis analíticos, fatores estruturadores e métodos

Fonte: Ferreira (2012a, p. 177) 


\section{Diagnóstico macroergonômico de QVT}

O primeiro nível analítico é o macroergonômico. Ele constitui o ponto de partida, um diagnóstico organizacional, na resposta à demanda do tipo "Como promover a QVT para todos os servidores de um dado órgão público?”. Nesse nível, a QVT se situa em um continuum das representações que os trabalhadores manifestam sobre o contexto de trabalho no qual eles estão inseridos. Tais representações, conforme ilustra o modelo, encontram-se polarizadas sob duas modalidades de representações de natureza afetiva: bem-estar no trabalho (positivas) e mal-estar no trabalho (negativas). Tais modalidades estão definidas, respectivamente, da seguinte forma:

- O bem-estar no trabalho é um sentimento agradável que se origina das situações vivenciadas pelo(s) indivíduo(s) na execução das tarefas. A manifestação individual ou coletiva do bem-estar no trabalho se caracteriza pela vivência de sentimentos (isolados ou associados) que ocorrem, com maior frequência, nas seguintes modalidades: alegria, amizade, ânimo, confiança, conforto, disposição, equidade, equilíbrio, estima, felicidade, harmonia, justiça, liberdade, prazer, respeito, satisfação, segurança, simpatia (FERREIRA, 2012a, p. 179);

- O mal-estar no trabalho é um sentimento desagradável que se origina das situações vivenciadas pelo(s) indivíduo(s) na execução das tarefas. A manifestação individual ou coletiva do mal-estar no trabalho se caracteriza pela vivência de sentimentos (isolados ou associados) que ocorrem, com maior frequência, nas seguintes modalidades: aborrecimento, antipatia, aversão, constrangimento, contrariedade, decepção, desânimo, desconforto, descontentamento, desrespeito, embaraço, incômodo, indisposição, menosprezo, ofensa, perturbação, repulsa, tédio (FERREIRA, 2012a, p. 180).

A vivência duradoura do sentimento de bem-estar pelos trabalhadores constitui um fator de promoção da saúde nas situações de trabalho e indica a presença de QVT. Em contrapartida, a vivência duradoura do mal-estar no trabalho constitui um fator de risco para a saúde e a segurança nas situações de trabalho e indica a ausência de QVT. A zona intermediária no continuum de representações indica a coabitação das duas modalidades de sentimentos. Não há, portanto, uma fronteira demarcadora evidente na qual, efetivamente, começam e terminam os sentimentos representacionais de bem-estar e de mal-estar no trabalho. No entanto, a produção dessas modalidades de representações nasce da experiência dos trabalhadores, construídas nas situações de trabalho, com base nos fatores apresentados no Quadro 1 (FERREIRA, 2012a).

A cultura organizacional que engloba os fatores se apresenta como uma espécie de "cenário" no qual estão imersos os atributos constituintes dos

Quadro 1 Fatores estruturantes das representações de bem-estar e mal-estar no trabalho

\begin{tabular}{|c|c|}
\hline Condições do Trabalho & $\begin{array}{l}\text { Equipamentos arquitetônicos (piso, paredes, teto, portas, janelas, decoração, arranjos físicos, } \\
\text { layouts); ambiente físico (espaços de trabalho, iluminação, temperatura, ventilação, acústica); } \\
\text { instrumental (ferramentas, máquinas, aparelhos, dispositivos informacionais, documentação, postos } \\
\text { de trabalho, mobiliário complementar); matéria-prima (materiais, bases informacionais); suporte } \\
\text { organizacional (informações, suprimentos, tecnologias, políticas de remuneração, de capacitação e } \\
\text { de benefícios). }\end{array}$ \\
\hline Organização do Trabalho & $\begin{array}{l}\text { Missão, objetivos e metas organizacionais (qualidade e quantidade, parametragens); divisão do } \\
\text { trabalho (hierárquica, técnica, social); processo de trabalho (ciclos, etapas, ritmos, tipos de pressão); } \\
\text { padrão de conduta (conhecimento, atitudes, habilidades previstas, higiene, trajes/vestimentas); } \\
\text { trabalho prescrito (planejamento, tarefas, natureza e conteúdos das tarefas, regras formais e } \\
\text { informais, procedimentos técnicos, prazos); tempo de trabalho (jornada [duração, turnos], pausas, } \\
\text { férias, flexibilidade); gestão do trabalho (controles, supervisão, fiscalização, disciplina). }\end{array}$ \\
\hline $\begin{array}{l}\text { Relações Socioprofissionais do } \\
\text { Trabalho }\end{array}$ & $\begin{array}{l}\text { Relações hierárquicas (chefia imediata, chefias superiores); relações com os pares (colegas de } \\
\text { trabalho, membros de equipes); relações externas (cidadãos-usuários dos serviços públicos, clientes e } \\
\text { fornecedores de produtos e serviços privados, prestadores de serviços, auditores, fiscais). }\end{array}$ \\
\hline $\begin{array}{l}\text { Reconhecimento e Crescimento } \\
\text { Profissional }\end{array}$ & $\begin{array}{l}\text { Reconhecimento (do trabalho realizado, do empenho, da dedicação, da hierarquia [chefia imediata } \\
\text { e superiores], da instituição, dos cidadãos-usuários / clientes / consumidores, da sociedade); } \\
\text { crescimento profissional (uso da criatividade, desenvolvimento de competências, capacitações, } \\
\text { oportunidades, incentivos, equidade, carreira). }\end{array}$ \\
\hline Elo Trabalho e Vida Social & $\begin{array}{l}\text { Sentido do trabalho (prazer, bem-estar, valorização do tempo vivenciado na organização, sentimento } \\
\text { de utilidade social, produtividade saudável); importância da instituição empregadora (significado } \\
\text { pessoal, significado profissional, significado familiar, significado social); vida social (relação trabalho- } \\
\text { casa, relação trabalho-família, relação trabalho-amigos, relação trabalho-lazer, relação trabalho- } \\
\text { sociedade). }\end{array}$ \\
\hline
\end{tabular}


fatores mencionados anteriormente. Ela fornece elementos conceituais estratégicos para avaliar a QVT no contexto organizacional. Tais elementos constitutivos são transversais e estruturadores dos contextos de trabalho e seus ingredientes principais são os seguintes: linguagem e simbolismo (jargões, padrões, estilos de comunicação [gestuais, verbais, escritos], códigos, produção de signos linguísticos, senso comum); comportamentos (inter-relação de ação e simbolismo, estilos de trabalho, perfis gerenciais, padrões de conduta e procedimentos, estilos de controle, modalidades de cooperação); valores organizacionais (respeito, cordialidade, disciplina, rigidez, equidade, fidelidade, continuidade, autonomia, liberdade, inovação); crenças (personalização das relações sociais [apadrinhamento], relação espaço público e espaço privado, jeitinho brasileiro, patrimonialismo na esfera pública, arquétipo do estrangeiro milagroso, interação social intensa, cordialidade de aparência afetiva, predominância do espírito coletivo, evitação de incertezas, modelo da grande família, gerência autocrática, pai patrão); ritos (entradas e saídas da organização, eventos culturais, rituais administrativos).

Para além dos contatos iniciais com os demandantes, com a análise documental e com a observação livre - passos bem característicos da primeira etapa da AET -, a abordagem metodológica no nível macroergonômico de avaliação de QVT tem como centralidade instrumental o uso do Inventário de Avaliação de Qualidade de Vida no Trabalho (IA_QVT), construído e validado por Ferreira (2009). O IA_QQVT combina uma parte quantitativa (escala psicométrica do tipo Likert, alfa =0,94, constituída de cinco fatores e 61 itens) e outra qualitativa (quatro questões abertas que tratam de QVT sob a ótica dos respondentes, a identificação das principais fontes de bem-estar e de mal-estar no trabalho e espaço livre de comentários e sugestões). Esse instrumento quanti-quali possibilita, principalmente, mapear as representações dos trabalhadores sobre: (a) os fatores estruturantes de QVT (p. ex.: como eles avaliam a organização do trabalho); (b) o modo coletivo de conceber QVT; (c) os elementos presentes nas situações de trabalho que caracterizam as principais fontes de bem-estar e de mal-estar.

O uso do IA QVT tem quatro vantagens de diagnóstico. Ele permite: (a) realizar um diagnóstico rápido, com rigor científico, de como os trabalhadores avaliam a QVT na organização em que trabalham; (b) gerar subsídios fundamentais para a concepção de política de QVT (fundamentos, marco conceitual, princípios) e de Programa de Qualidade de Vida no Trabalho (PQVT) (diretrizes, projetos, ações) com base nas expectativas e necessidades apontadas pelos respondentes; (c) identificar indicadores (comportamentais, epidemiológicos e perceptivos) de QVT que auxiliam na gestão do PQVT; (d) servir de instrumento auxiliar de monitoramento longitudinal de QVT na organização. Entretanto, a principal vantagem do uso do IA_QVT na abordagem da EAA_QVT consiste em aprofundar e em refinar a demanda inicial dos interlocutores, fornecendo as bases empíricas para o diagnóstico microergonômico, desta vez com no uso da AET clássica. É nessa perspectiva que se situa, portanto, o lugar e a importância da AET para a avaliação da QVT, posto que o limite metodológico principal do IA_QVT é tão somente identificar a "ponta do iceberg” do olhar dos trabalhadores sobre a QVT em uma dada organização. Compreender, por exemplo, como os trabalhadores lidam com a pressão por resultados - um indicador constatado pelo IA_QVT - requer avançar para um nível analítico microergonômico das situações de trabalho nas quais entra em cena o papel estratégico da AET.

\section{Diagnóstico microergonômico de QVT: lugar, importância e contribuição da AET}

A “fotografia” produzida no diagnóstico macroergonômico de QVT fornece as bases empíricas para a definição e para a escolha da "situação-problema" que pode ser mais de uma e ser investigada com o uso da AET. Nesse nível, é chegada a hora da análise da atividade dos trabalhadores nas situações de trabalho. A condução dessa etapa é feita com base em planejamento criterioso que engloba instrumentos e procedimentos típicos da AET: (a) análise documental; (b) observação aberta; (c) entrevistas individuais e coletivas, neste último caso usando a técnica de grupos focais; (d) observações sistemáticas; (e) quando necessário, mensuração físico-ambiental (p. ex.: avaliação de conforto acústico) e uso de instrumentos complementares de diagnóstico (p. ex.: checklist de usabilidade de interfaces).

Nesse nível analítico da EAA_QVT, o objetivo é aprofundar a investigação para produzir dados empíricos consistentes e robustos para a demanda inicial do tipo "Como promover a QVT para todos os servidores de um dado órgão público?”. Essa etapa metodológica buscará produzir um cenário explicativo, de natureza dinâmica, de como se configura situações de trabalho que colocam em risco a saúde e a segurança dos trabalhadores. Conforme ilustra a Figura 1, o primeiro passo consiste em mapear o Custo Humano do Trabalho (CHT), assim definido por Ferreira (2012a, p. 186): “[...] ele expressa o que deve ser despendido pelos trabalhadores (individual e coletivamente) nas esferas física, cognitiva e afetiva a fim de responderem às exigências de tarefas (formais e/ou informais) postas nas situações de trabalho."

Tais esferas são reveladoras de três modalidades de CHT, ao mesmo tempo, específicas e interdependentes: 
(a) as exigências físicas se referem, globalmente, ao custo corporal em termos de dispêndios fisiológico e biomecânico, principalmente, sob a forma de posturas, gestos, deslocamentos e emprego de força física; (b) as exigências cognitivas, por sua vez, dizem respeito ao custo cognitivo em termos de dispêndio mental sob a forma de atenção necessária, do uso da memória, forma de aprendizagem requerida, de resolução de problemas e de tomada de decisão; (c) as exigências afetivas estabelecem o custo afetivo em termos de dispêndio emocional sob a forma de reações afetivas, de sentimentos vivenciados e de estado de humor manifesto.

As contradições vivenciadas cotidianamente pelos trabalhadores nas situações de trabalho que tornam complexa a atividade dos trabalhadores (p. ex.: pressão por produtividade que compromete a qualidade do produto e/ou serviço) e, muitas vezes, colocam no limite as suas capacidades físicas, cognitivas e afetivas são configuradoras do CHT nos contextos corporativos. O CHT, nessa ótica, engloba as propriedades humanas do pensar, do agir e do sentir, que caracterizam, por seu turno, os modos de ser e de viver dos trabalhadores nos contextos corporativos fortemente presentes na cultura organizacional. Na abordagem da EAA_QVT, o CHT apresenta três características principais:

- Ele é imposto externamente aos trabalhadores, em face das características do contexto de produção, sob a forma de constrangimentos para suas atividades;

- Ele é gerido por meio das estratégias de mediação individual e coletiva (atividades) que visam, principalmente, responder à discrepância entre as tarefas prescritas pelos modelos de gestão e as situações reais de trabalho;

- Ele está na origem da produção de representações mentais de bem-estar e de mal-estar que os trabalhadores constroem com base nos efeitos do CHT (FERREIRA, 2012a, p. 186).

Com base no mapeamento do CHT, o segundo passo no diagnóstico microergonômico consiste em colocar a "lupa" da AET para compreender como os trabalhadores regulam as exigências presentes nas situações de trabalho, as quais, por sua vez, são configuradores do perfil do CHT. Deve-se investigar, sobretudo, o modo como os trabalhadores lidam (a atividade) com os múltiplos constrangimentos, visando vivenciar o bem-estar no trabalho, evitar os riscos de adoecimento e de acidentes e, ao mesmo tempo, garantir os objetivos prescritos do trabalho. Conforme ilustra a Figura 1, a atividade dos trabalhadores expressa, conceitualmente, as estratégias operatórias de mediação individual e coletiva. Essa categoria está assim definida:
Elas expressam os "modos de pensar, sentir e de agir" dos trabalhadores em face das situações vivenciadas. Elas visam responder do melhor modo possível (modos operatórios pertinentes) à diversidade de contradições que caracteriza e impacta no custo humano do trabalho, prevenindo as vivências de mal-estar no trabalho e instaurando, em contrapartida, as vivências de bem-estar no trabalho. (FERREIRA, 2012a, p. 187).

Esse enfoque de estratégias de mediação se apoia na noção de agir finalístico em termos de regulação (FAVERGE, 1993; LEPLAT, 1993) e de equilibração (WEILL-FASSINA, 1972; PIAGET, 1975; GROSJEAN; WEERDT, 2005), que os trabalhadores operacionalizam visando manter o equilíbrio e assegurar o funcionamento correto de um sistema, por definição, complexo de trabalho. Nessa perspectiva, a atividade dos trabalhadores em face das tarefas é inseparável do trabalho intelectual específico, o qual os possibilita, de maneira prévia, organizar cognitivamente modos de agir para que respondam às exigências presentes nas situações de trabalho (TEIGER, 1993; WEILL-FASSINA, 1998).

Na abordagem EAA_QVT (Figura 1), o conhecimento produzido pelo uso da AET, dando visibilidade às estratégias operatórias de mediação dos trabalhadores (gênese, dinâmica, características) para que eles possam lidar com os constrangimentos vivenciados nas situações de trabalho (sobretudo, as duas resultantes principais: eficácia e ineficácia das condutas de regulação), permite completar o ciclo descritivo de avaliação da QVT, proposta no modelo teórico. A AET possibilita, portanto, conhecer as causas mais profundas que estão na origem do mal-estar no trabalho (que potencializa o risco de adoecimento e de acidentes) e do bem-estar no trabalho (que materializa as vivências de QVT). É neste "ponto de chegada" que os níveis analíticos do diagnóstico ergonômico (o macro e o micro) dialogam e se complementam. É possível afirmar, metaforicamente, que o diagnóstico macroergonômico mostra a ponta do iceberg e o diagnóstico microergonômico permite conhecer o que está na base desse mesmo iceberg. Assim, no desvendamento do objeto da demanda (promoção da QVT), a principal contribuição AET é possibilitar a transição dialética da aparência à essência, mostrando em que contextos os constrangimentos existentes nas situações de trabalho são prejudiciais à QVT.

O trajeto metodológico típico que nasce da aplicação do modelo teórico está ilustrado na Figura 2. Nele é possível identificar as três etapas principais de investigação na abordagem EAA_QVT, a qual tem como "ponto de partida" a demanda evocada no relato sobre a sua gênese. A descrição detalhada desse modelo metodológico pode ser visto em Ferreira (2012a).

Nessa abordagem metodológica, a AET tem lugar de destaque e sua importância é crucial para se compreender as causas mais profundas dos indicadores negativos ou positivos, constatadas na etapa do 


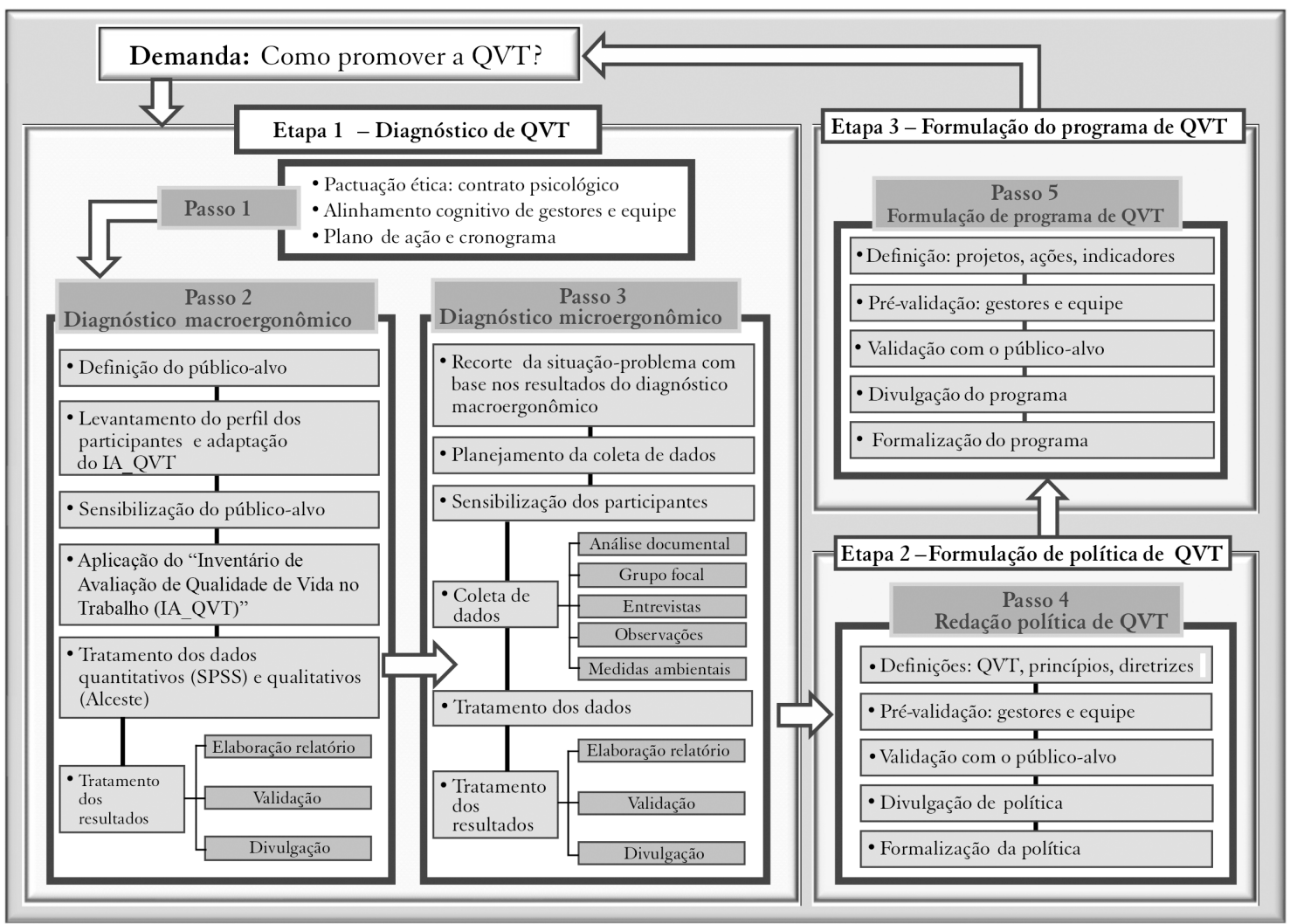

Figura 2 Modelo metodológico em ergonomia aplicada à qualidade de vida no trabalho Fonte: Ferreira (2012a, p. 201)

diagnóstico macroergonômico. Causas que, por sua vez, influenciam decisivamente a QVT nos ambientes de trabalho. Sua contribuição é, portanto, estratégica para o desenho de soluções sob as modalidades de política (fundamentos, conceito, princípios) e de programa (diretrizes, projetos, ações) de QVT para as organizações. Essas soluções buscam operacionalizar o pressuposto de compreender o trabalho para transformá-lo.

O relato sucinto, a seguir, de um case de aplicação da EAA_QVT, a título de ilustração, permite ver e situar a contribuição da AET como instrumento de diagnóstico para investigar a QVT.

\section{Cobrança excessiva e repetitividade: a organização do trabalho na origem do mal-estar}

A condução da abordagem da EAA_QVT foi realizada por Figueira (2011) e por Daniel (2012) em um órgão público federal brasileiro. No diagnóstico macroergonômico (na Figura 2, ver passo dois), participaram 520 trabalhadores (40\% da população) presentes no órgão no período da coleta de dados.
O tratamento dos resultados produzidos pelo IA_QVT mostrou que o fator "Organização do Trabalho" foi o avaliado mais negativamente pelos respondentes. Nesse caso, dois aspectos se destacaram como os mais problemáticos na ótica dos trabalhadores: "cobrança [excessiva] de prazos para o cumprimento de tarefas" e "tarefas repetitivas". Tais aspectos, entre outros, destacaram-se como fontes de mal-estar no trabalho e, portanto, potencializando o risco de adoecimento dos trabalhadores.

\section{Desenvolvimento da AET e seus produtos}

Com bases nesses resultados, os passos metodológicos da AET colocada em curso englobaram diversas atividades: (a) levantamento das possíveis unidades administrativas para ser campo de coleta de dados; (b) contato com os gestores para formalizar o "contrato" de condução da AET (objetivos, etapas, produtos, devolutiva, validação, implicações deontológicas); (c) planejamento da coleta de dados; (d) recorte da "situação-problema" e escolha do setor específico na unidade administrativa predefinida; (e) sensibilização dos participantes, fornecendo uma visão panorâmica da AET e esclarecendo sobre a importância do 
projeto; (f) observação livre; (g) análise documental sobre o perfil da unidade administrativa escolhida, especialmente as características do trabalho prescrito; (h) entrevistas individuais; (i) observação sistemática de situações de trabalho; (j) tratamento dos dados coletados; (k) devolutiva de validação dos resultados com os participantes; (l) elaboração de relatório final e recomendações.

\section{Unidade administrativa e participantes}

Com base nesse trajeto metodológico da AET, o público-alvo do diagnóstico microergonômico no órgão foram 52 trabalhadores lotados em uma coordenação vinculada ao apoio à pesquisa (atividade fim), distribuídos em três gerências. Nessa coordenação, participaram da AET 34 servidores. O perfil demográfico e profissiográfico apresentou as seguintes características: $76 \%$ dos servidores com idade entre 41 a 60 anos; equilíbrio entre homens e mulheres; $56 \%$ dos servidores com tempo de serviço no órgão na faixa de 21-33 anos; $58 \%$ dos servidores com escolaridade de pós-graduação. Dois traços merecem registro nesse perfil: a alta escolaridade e a maioria com bastante "tempo de casa". Neste último caso, trata-se de participantes portadores de uma vivência (experiência) importante de trabalho.

\section{Coleta de dados na etapa do diagnóstico microergonômico}

Foram entrevistados seis servidores (dois de cada gerência que compunha a coordenação), cujo perfil é o seguinte: média de 42,5 anos (variância de 30 a 60 anos); escolaridade: um com doutorado, três com doutorado incompleto, um com mestrado e um com ensino médio; sexo: três homens e três mulheres; estado civil: quatro eram casados, um era divorciado e um era solteiro; tempo no serviço público federal: média de 14,5 anos (variância de 3 a 38 anos); tempo no órgão: média de 13,3 anos (variância de 2 a 32 anos). As observações sistemáticas foram realizadas com base no acompanhamento da rotina de trabalho (relato cursivo) de dois servidores, tendo como "bússola" dois dos resultados da aplicação do IA_QVT concernentes à "cobrança [excessiva] de prazos para o cumprimento de tarefas" e às "tarefas repetitivas".

\section{Principais resultados}

O tratamento dos dados e a devolutiva de validação dos resultados com os participantes permitiram construir um quadro explicativo sobre os aspectos negativos constatados no diagnóstico macroergonômico relativos à organização do trabalho. A análise da situação-problema investigada possibilitou delinear o perfil do CHT e as estratégias operatórias de mediação dos trabalhadores para gerirem os constrangimentos vivenciados no âmbito da organização do trabalho.

\section{Perfil do trabalho prescrito}

Constatou-se, com base no levantamento documental, a inexistência de qualquer normativo que descrevesse especificamente as tarefas e os procedimentos administrativos que deveriam ser utilizados pelos servidores. Portanto, toda a caracterização do trabalho prescrito foi realizada por meio de entrevistas com os participantes. As principais características do processo de trabalho são as seguintes: (a) as tarefas, sob o formato de processos, são distribuídas automaticamente aos servidores por meio da disponibilização de mensagens enviadas às caixas virtuais de trabalho; (b) a execução global das tarefas deve estar em consonância com um aparato jurídico, o qual parametriza a execução das atividades (p. ex.: portarias); (c) o fluxo típico da organização do trabalho pode ser ilustrado pela tarefa "implementação de verbas e subsídios", cujas etapas são as seguintes: recebimento da tarefa; enquadramento administrativo; indicação para análise por pares; julgamento por experts; acompanhamento; finalização de relatório.

O suporte da informática ocupa lugar central na execução das tarefas, as quais são feitas por meio de aplicativos projetados para a gestão administrativa dos processos (p. ex.: controle de prazos). A carga de trabalho é gerida com base, fundamentalmente, em dois critérios: quantidade de processos e prazos estabelecidos para finalização. A gestão do andamento dos processos é feita pela analogia com um semáforo: verde $=$ há prazo; amarelo = prazo finalizando; vermelho $=$ prazo encerrado.

Ingredientes típicos das situações de trabalho e suas exigências

O acompanhamento da execução das tarefas dos servidores, por meio da observação sistemática do tipo relato cursivo em situações de trabalho (registro em tempo real de comportamentos, fatos etc.), permitiu identificar os seus traços característicos e suas exigências inerentes:

- Rotina de trabalho fortemente informatizada: a distribuição dos processos é feita por meio de correio eletrônico e o seu tratamento se opera por meio de aplicativos. Um servidor afirmou: "Eu trabalho 100\% do tempo no computador."; 
- Processo de trabalho repetitivo: o tratamento informatizado implica em ações e operações administrativas muito repetitivas. "É extremamente repetitiva [a tarefa: ficar clicando]”, desabafou um servidor (colchetes nossos);

- Volume excessivo de trabalho e pressão temporal: a intensificação do trabalho é marcada pela combinação entre a quantidade de processos, os prazos estabelecidos e a sazonalidade das demandas. Algumas verbalizações são ilustrativas desses aspectos: "Às vezes, a demanda é muito alta e você tem um período de tempo muito curto para fazer aquilo.”; “Tem pressão o tempo todo.”; “A pressão não é da hierarquia em si; a pressão é do próprio sistema que exige cumprir aqueles objetivos em determinado período.";

- Divisão desigual do trabalho e falta de pessoal: a falta de pessoal agrava o processo de divisão de tarefas entre os servidores, agregando mais complexidade para a gestão das exigências das tarefas e constrangimentos vivenciados nas situações de trabalho. Os servidores afirmam: "A gente vê que tem setores da casa que tem bastante gente e que dão conta tranquilo do serviço, enquanto tem setores que estão sobrecarregados, que são poucos funcionários com muito serviço." e "Falta gente demais!”;

- Interface pouco amigável dos aplicativos: um trabalho fortemente informatizado, todavia os aplicativos apresentam interfaces com usabilidade limitada, problemática. Duas verbalizações servem de exemplos dos problemas existentes: "A gente tem três sistemas. Tem informação que você só consegue no sistema mais antigo, então você tem que ficar procurando essas coisas." e "Às vezes dá um 'pau danado' que o sistema se perde, eu tenho que começar tudo de novo.”.
Os dados coletados pela AET possibilitaram mapear, portanto, os principais tipos de constrangimentos vivenciados pelos servidores e, em consequência, os impactos desses problemas sobre as vivências de mal-estar e suas repercussões para a QVT.

Perfil do Custo Humano do Trabalho e as estratégias de mediação dos servidores

Os diversos constrangimentos, característicos das situações de trabalho investigadas, que marcam o cotidiano dos servidores deram visibilidade ao perfil do CHT e das estratégias operatórias típicas, como mostra o Quadro 2.

É nesse cenário característico que a QVT fica comprometida. O trabalho se transforma mais em vivências de mal-estar, colocando em risco a saúde dos servidores e, em decorrência, os próprios objetivos organizacionais. Configura-se, portanto, um cenário em que todos perdem: os servidores, os gestores, o órgão e, por efeito cascata, os usuários dos serviços.

As falas dos servidores, que nascem da aplicação da AET, agregam inteligibilidade sobre os impactos dos constrangimentos vivenciados e geradores de mal-estar no trabalho (grifo nosso): "Uma coisa que é um clamor dos analistas, assim de forma generalizada, é que a gente queria fazer um trabalho mais pensante."; "A gente gosta de ter desafios, de tentar buscar novas alternativas para melhorar... Você não tem estímulo neste sentido."; "Hoje mesmo, a gente tentou mandar um e-mail carinhoso, porque eu estava dividindo mais tarefas."; "É repetitivo, você fica clicando $20 \mathrm{mil}$ bolinhas, digitando muita coisa.”; “[...] a gente tem uma tendência a ter umas dores no braço, eu já aprendi a mudar o mouse."; "Para não perder tempo, eu vou abrindo janelas."

Globalmente, os resultados produzidos no diagnóstico microergonômico, por meio da AET, possibilitaram construir um quadro explicativo mais completo e

Quadro 2 Exigências do custo humano e modos operatórios típicos dos servidores

\begin{tabular}{|l|l|l|}
\hline \multicolumn{2}{|c|}{ Custo Humano do Trabalho } & \multicolumn{1}{c|}{ Exemplos de Modos Operatórias } \\
\hline Exigências Físicas & $\begin{array}{l}\text { Solicitação intensa de mãos, braços e postura } \\
\text { sentada por tempo prolongado no uso do } \\
\text { computador. }\end{array}$ & $\begin{array}{l}\text { Alternam a posição do mouse. Procuram fazer pausas } \\
\text { (alternativa difícil em face do volume de trabalho e } \\
\text { da pressão temporal dos prazos existentes). }\end{array}$ \\
\hline Exigências Cognitivas & $\begin{array}{l}\text { Automatismo. Sobrecarga informacional. Pressão } \\
\text { temporal para tratar informações. }\end{array}$ & $\begin{array}{l}\text { Criam diversas “janelas” para compensar o } \\
\text { tratamento lento de uma tarefa pelo sistema } \\
\text { informatizado. Buscam obter o suporte da área de } \\
\text { informática. }\end{array}$ \\
\hline Exigências Afetivas & $\begin{array}{l}\text { Autocontrole emocional para gerir a irritabilidade, } \\
\text { a ansiedade, o desânimo e a frustração provocadas, } \\
\text { principalmente, pela cobrança excessiva de prazos e } \\
\text { tarefas repetitivas. }\end{array}$ & $\begin{array}{l}\text { Agregam afeto nos modos de gerir o relacionamento } \\
\text { socioprofissional com os colegas (p. ex. formas } \\
\text { afetuosas de abordagens e de divisão de trabalho). }\end{array}$ \\
\hline
\end{tabular}

Rev. bras. Saúde ocup., São Paulo, 40 (131): 18-29, 2015 
robusto no que concerne aos resultados gerados pela aplicação do IA_QVT na etapa do diagnóstico macroergonômico. A AET permitiu compreender de forma mais dinâmica os ingredientes e as formas de manifestação das queixas (pontas do iceberg no diagnóstico macroergonômico) relativos à "cobrança [excessiva] de prazos para o cumprimento de tarefas" e às "tarefas repetitivas", apontadas pelos respondentes do IA_QVT. Tais resultados evidenciados pela AET forneceram valiosos subsídios empíricos aos dirigentes, aos gestores e aos técnicos para a formulação de projetos e para a implementação de ações de QVT (p. ex.: aprimoramento de interfaces dos aplicativos), no âmbito da organização do trabalho, como modo de atenuar e/ou remover as fontes do mal-estar no trabalho, constatadas entre os servidores.

\section{Conclusão}

A visão panorâmica da abordagem EAA_QVT permitiu situar nessa abordagem o lugar estratégico, a importância e a contribuição da AET para a investigação da QVT. O relato da experiência de aplicação da EAA_QVT, por meio de um caso, buscou mostrar o uso do modelo teórico-metodológico como instrumento heurístico para avaliação da QVT. Nesse contexto, o uso da AET no campo da QVT revela importantes contribuições:

- A EAA QVT e a sua abordagem multimétodo (BOLÍVAR, 2008), que combina investigação de caráter quanti-quali e dois níveis analíticos complementares (diagnósticos macro e microergonômico), podem se constituir em uma alternativa para a produção de conhecimentos sobre QVT com base no enfoque da AET, sobretudo no que tange ao lugar central da atividade e do ponto de vista dos trabalhadores;

- A AET pode ser forte aliada para o conhecimento das causas mais profundas das vivências de malestar e de bem-estar no trabalho, balizadoras da presença ou não da QVT nos ambientes corporativos;
- A análise das situações reais de trabalho - seus ingredientes, sua dinâmica e seus obstáculos constrangedores que servem de contexto para situar o CHT e para compreender as estratégias operatórias dos trabalhadores, seus limites e suas possibilidades - é recurso instrumental imprescindível para a compreensão dos fatores que impactam na QVT para além de sua aparência;

- A produção de recomendações para a transformação positiva das situações de trabalho, de caráter sustentável, voltadas para a efetiva promoção da QVT, mostra limites epistemológicos de delineamentos metodológicos quando feito exclusivamente com o uso de questionários e de entrevistas.

O uso da EAA_QVT revela limites, pois ainda está em construção, e, paulatinamente, vem acumulando experiências de sua aplicação, ainda restritas ao setor público brasileiro. Novas aplicações dessa abordagem, certamente, permitirão promover ajustes teóricos (p. ex.: operacionalizar o constructo reconhecimento no trabalho) e metodológicos (p. ex.: aprimorar o IA_QVT) no diálogo saudável com as outras ciências do trabalho e da saúde (p. ex.: sociologia clínica, psicodinâmica do trabalho). O uso cauteloso do modelo teórico-metodológico que serve de sustentação requer a compreensão de seus limites como heurística para investigar a QVT. Ele deve ser mais "ponto de partida”, estruturador do caminhar metodológico, que "ponto de chegada" do processo de investigação. Como "ponto de chegada", os conhecimentos produzidos devem permitir aprimorar o modelo e mostrar os seus limites diversos, específicos e suas implicações deontológicas.

A perspectiva de aplicação da EAA_QVT - situando o lugar, a importância e a contribuição da AET - poderá ser geradora, nas organizações, de fundamentos empíricos e teóricos para a formulação de políticas e de programas de QVT, as quais possam alterar positivamente o cenário atual do mundo trabalho, que se apresenta fortemente marcado pela intensificação do trabalho e por mazelas diversas que "roubam" da atividade trabalho o seu caráter ontológico de produtor da felicidade.

\section{Referências}

AMALBERTI, R.; MONTMOLLIN, M.; THEUREAU, J. Modèles en analyse du travail. Liège: Mardaga, 1991.

ANTUNES, R.; ALVES, G. As mutações no mundo do trabalho na era da mundialização do capital. Educação \& Sociedade, Campinas, v. 25, n. 87, p. 335351, 2004.

BOLÍVAR, C. R. El enfoque multimétodo en la investigación social y educativa: una mirada desde el paradigma de la complejidad. Teré: revista de filosofía y socio-política de la educación, Venezuela, v. 4, n. 8, p. 13-21, 2008.

DANIEL, J. B. É-feito de coisas burocráticas: impactos da organização do trabalho para a qualidade de vida no trabalho num órgão público federal. 2012. 123 f. Dissertação (Mestrado em Psicologia Social e do Trabalho)-Departamento de Psicologia e do Trabalho, Universidade de Brasília, Brasília, DF, 2012. 
DANIELLOU, F. Questions épistémologiques autour de l'ergonomie. In: (Org.). L'ergonomie en quête de ses principes. Débats épistémologiques. Toulouse: Octarès, 1996. p. 1-17.

FAVERGE, J. M. L'analyse du travail em terme de régulation. In: LEPLAT, J. (Org.). L'analyse du travail en psychologie ergonomique. Recueil de textes. Toulouse: Octarès, 1993. t. 1, p. 61-86.

FERREIRA, M. C. A ergonomia da atividade pode promover a Qualidade de Vida no Trabalho? Reflexões de natureza metodológica. Revista Psicologia: Organizações e Trabalho (rPOT), Florianópolis, v. 11, n. 1, p. 8-28, 2011.

FERREIRA, M. C. A ergonomia da atividade se interessa pela Qualidade de Vida no Trabalho? Reflexões empíricas e teóricas. Cadernos de Psicologia Social do Trabalho (USP), São Paulo, v. 11, n. 1, p. 8399, 2008.

FERREIRA, M. C. Inventário de Avaliação da Qualidade de Vida no Trabalho (IA_QVT): instrumento para diagnóstico e planejamento. In: FÓRUM INTERNACIONAL DE QUALIDADE DE VIDA NO TRABALHO, 11., 2009, Porto Alegre. Anais... Porto Alegre: ISMA, 2009. CD-ROM.

FERREIRA, M. C. Ofurô corporativo. Brasília, DF: Universidade de Brasília, 2006. Disponível em: $<$ http://www.unb.br/noticias/unbagencia/artigo. php?id=202>. Acesso em: 2 fev. 2013.

FERREIRA, M. C. Qualidade de Vida no Trabalho: uma abordagem centrada no olhar dos trabalhadores. 2. ed. rev. e ampl. Brasília, DF: Paralelo 15, $2012 \mathrm{a}$.

FERREIRA, M. C. Qualidade de vida no trabalho. In: CATTANI, A. D.; HOLZMANN, L. (Org.). Dicionário de trabalho e tecnologia. 3. ed. Porto Alegre: Zouk, 2012b. p. 219-222.

FERREIRA, M. C.; ARAÚJO, D. L. M.; ARAÚJO, F. B. O. A teoria e a prática no trabalho do caixa de supermercado. In: REUNIÃO ANUAL DE PSICOLOGIA DA SBP, 18., 1998, Ribeirão Preto. Anais... Ribeirão Preto: SBP, 1998. p. 143.

FIGUEIRA, T. G. Relatório técnico do diagnóstico de qualidade de vida no trabalho em órgão público federal. Brasília, DF: Universidade de Brasília, 2011.

FREIRE, O. N.; FERREIRA, M. C. A empresa Treina, mas na prática é outra coisa: carga de trabalho do frentista e a rotatividade na função de frentista. In: ENCONTRO PAN-AMERICANO DE ERGONOMIA, 1., 2000, Rio de Janeiro. Anais... Rio de Janeiro: ABERGO, 2000. p. 1.
GONÇALVES, R. M.; FERREIRA, M. C. Serviço de atendimento ao público e home-pages governamentais. In: CONGRESSO LATINOAMERICANO DE ERGONOMIA, 5., 1999, Salvador. Anais... Salvador: ABERGO, 1999. CD-ROM.

GROSJEAN, V.; WEERDT, C. R. Vers une psychologie ergonomique du bien-être et des émotions: les effets du contrôle dans les centres d'appels. Le Travail Humain, Paris, v. 68, n. 4, p. 355-378, 2005.

GUÉRIN, F. et al. Comprendre le travail pour le transformer. La pratique de l'ergonomie. 2. ed. Lyon: Editions ANACT, 1997. (Collection Outils et Méthodes).

LACAZ, F. A. C. Qualidade de vida no trabalho e saúde/doença. Ciência \& Saúde Coletiva, Rio de Janeiro, v. 5, n. 1, p. 151-161, 2000. http://dx.doi. org/10.1590/S1413-81232000000100013.

LAVILLE, A. L'ergonomie. 5. ed. Paris: PUF, 1993.

LEITE, M. P. Trabalho e sociedade em transformação: mudanças produtivas e atores sociais. São Paulo: Fundação Perseu Abramo, 2003.

LEPLAT, J. Les répresentations fonctionnelles dans le travail. In: (Org.). L'analyse du travail en psychologie ergonomique. Toulouse: Octarès, 1993. p. 107-120. (Recueil de textes, t. 1).

MONTMOLLIN, M. L’ergonomie. Paris: Editions La Découverte, 1990.

PIAGET, J. L'équilibration des structures cognitives: problème central du développement. Paris: PUF, 1975. (Etudes d'épistémologie génétique).

TEIGER, C. Répresentation du travail et travail de la représentation. In: WEILL-FASSINA, A.; RABARDEL, P.; DUBOIS, D. (Org.). Représentations pour l'action. Toulouse: Éditions Octarès, 1993. p. 311-345.

WEILL-FASSINA, A. La notion de régulation en psychologie du travail: Définitions et cadres généraux. Bulletin de Psychologie, Paris, v. 25, n. 298, p. 546-551, 1972.

WEILL-FASSINA, A. Développement des représentations et des modalités de gestion en fonction de l>expérience professionnelle. In: ACTES DU SÉMINAIRE VIEILLISSEMENT-TRAVAIL, 1998, Paris. Proceedings... Paris: Cahiers du CRÉAPT, 1998. Não paginado.

WEILL-FASSINA, A.; RABARDEL, P.; DUBOIS, D. Représentations pour l'action. Toulouse: Octarès, 1993.

WISNER, A. A inteligência no trabalho: textos selecionados de ergonomia. São Paulo: Fundacentro, 1994. 